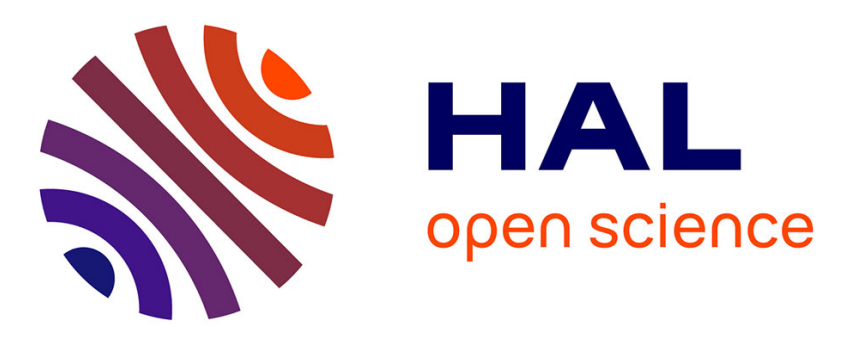

\title{
Supported plasma-made 1D heterostructures: perspectives and applications
}

\author{
Ana Borras, Manuel Macias-Montero, Pablo Romero-Gomez, Agustin R \\ Gonzalez-Elipe
}

\section{- To cite this version:}

Ana Borras, Manuel Macias-Montero, Pablo Romero-Gomez, Agustin R Gonzalez-Elipe. Supported plasma-made 1D heterostructures: perspectives and applications. Journal of Physics D: Applied Physics, 2011, 44 (17), pp.174016. 10.1088/0022-3727/44/17/174016 . hal-00613276

\section{HAL Id: hal-00613276 https://hal.science/hal-00613276}

Submitted on 4 Aug 2011

HAL is a multi-disciplinary open access archive for the deposit and dissemination of scientific research documents, whether they are published or not. The documents may come from teaching and research institutions in France or abroad, or from public or private research centers.
L'archive ouverte pluridisciplinaire HAL, est destinée au dépôt et à la diffusion de documents scientifiques de niveau recherche, publiés ou non, émanant des établissements d'enseignement et de recherche français ou étrangers, des laboratoires publics ou privés. 


\title{
Supported plasma made 1D heterostructures: perspectives and applications.
}

\author{
Ana Borras, ${ }^{*}$ Manuel Macias-Montero, Pablo Romero-Gomez and Agustin R. \\ Gonzalez-Elipe
}

Materials Science Institute of Seville (CSIC-Universidad Sevilla), C/ Américo Vespucio 49 41092, Sevilla (Spain)

\begin{abstract}
Plasma related methods have been widely used in the fabrication of carbon nanotubes and nanofibres and semiconducting inorganic nanowires. A natural progression of the research in the field of $1 \mathrm{D}$ nanostructures is the synthesis of multicomponent nanowires and nanofibres. In this article we review the state of the art of the fabrication by plasma methods of 1D heterostructures including applications and perspectives. Furthermore, recent developments on the use of metal seeds (Ag, Au, Pt) to obtain metal@oxide nanostructures are also extensively described. Results are shown for various metal substrates, either metal foils or supported nanoparticles/thin films of the metal where the effects of the size, surface coverage, percolation degree and thickness of the metal seeds have been systematically evaluated. The possibilities of the process are illustrated by the preparation of nanostructured films and supported nanofibres of different metal@oxides ( $\mathrm{Ag}, \mathrm{Au}$ and $\mathrm{SiO}_{2}, \mathrm{TiO}_{2}, \mathrm{ZnO}$ ). Particularly, in the case of silver, the application of an oxygen plasma treatment prior to the deposition of the oxide was critical for efficiently controlling the growth of the 1D heterostructures. A phenomenological model is proposed to account for the thin film nanostructuring and fibre formation by considering basic phenomena like stress relaxation, inhomogeneities in the plasma sheath electrical field and the local disturbance of the oxide growth.
\end{abstract}

\section{Introduction}

Classical thin film deposition methods using vacuum based technologies, and particularly plasma related methods, are generally intended to get very compact thin films. This has been traditionally the case when dealing with mechanical (e.g., hard and friction resistant coatings), protective (e.g., corrosion resistant coatings) or optical (e.g., high refraction index materials) applications $[1,2]$. To get a high compactness, there are several experimental approaches with the common concept of energetically exciting the arriving particles to enhance their mobility and rearrangement within the bulk of the film. The ion beam assisted procedures are a clear example of this approach [3]. However, the advent of new applications based on the use of nanostructured and porous 
thin films or other surface nanostructures (e.g., superhidrophobic/superhydrophilic surfaces, dye synthesized and hybrid solar cells, photocatalytic devices, electrodes for electrochemical and photo-electrochemical cells, piezoelectric brushes, fluorescent devices and other examples in electronics and photonics has fostered the development of new deposition procedures or the modification of the existing ones with the purpose of getting efficient methodologies of surface and thin film nanostructuring [4-6] and the preparation of supported 1D nanostructures such as nanowires (NWs), nanofibres (NFs), nanoribbons, nanotubes (NTs), etc. [7-12]. Numerous examples are available in the most recent literature where different supported 1D nanostructures are prepared by using wet chemical and electrochemical routes [13], vapour phase condensation methods (e.g. vapour-liquid-solid, VLS methods) [14], solution-phase methods [15], template directed synthesis [16] or other evaporation based approaches [17, 18], etc. An important advantage of the 1D over the 2D nanostructures and thin films is the facile fabrication of 1D defect-free heterostructures, and the tailored synthesis of multicomponent materials and heterojunctions with controlled 1D morphology (e.g., core@shell nanofibres, metal decorated CNTs and oxide nanowires, nanobrushes, segmented, cross junctions or branched 1D nanostructures) [10, 19-21].

On other hand, plasma deposition and, in general, plasma processing have been successfully used for the surface nanostructuring of materials and, to a much lesser extent, for the preparation of supported 1D nanostructures, although a deeper understanding of the physical phenomena involved in the development of these nanostructures is still needed [22]. For example, quite interesting plasma based methods have been developed for the preparation of oxide NFs and nanorodos [23, 24], nanoparticles [25] or the formation of deposited vertically aligned carbon nanotubes (CNTs) [26-29]. In this case, the last achievements in the formation of these nanostructures have enabled the fabrication of devices like flat panel displays, X-ray sources, etc. A common feature for the plasma fabrication of carbon nano-structures is the need of supported metal particles. Besides other phenomena, the effect of the metal nanoparticles has been discussed in terms of a catalytic action favouring the arrangement and diffusion of the carbon species arriving to the surface from the plasma phase $[28,29]$.

Plasma assisted methodologies present significant advantages over classical sol-gel, and other chemical and physical vapour deposition processes. Recent advances in this emerging topic of plasma-assisted fabrication of nanostructures are stressed in excellent 
reviews on the subject [30]. Among the advantages of plasma processes, it has been quoted that they are relatively low cost procedures, environmentally friendly (i.e., solventless method) and scalable at wafer scale for direct deposition onto electronic and photonic devices while providing a precise control over the composition of the deposited materials. Due to these advantages, during the last years plasma technology has being systematically used for the fabrication of 1D nanofibres and other heterostructures $[25,29-47]$. As already mentioned, most works in this field deal with the fabrication of heterostructures formed by CNTs and carbon nanofibers where the metal particle acts as a catalyst of the growth process. Just as examples of this type of heterostructures let us mention the case of Co nanoparticles encapsulated in CNTs that were synthesised by a one-step PECVD method at high pressures and substrate temperatures [32], that of Ti-coated CNTs fabricated by inductively-coupled plasma enhanced chemical vapour deposition (ICP-CVD) and Ti sputtering for field emission applications [33-35] or $\mathrm{Cu}-\mathrm{C}$ hybrid nanosystems produced by means of plasma deposition of carbon on copper metal seeds [28]. The results of Penza et al. about the decoration of CNTs with metal ( $\mathrm{Ag}, \mathrm{Au}, \mathrm{Pt}$ and $\mathrm{Ru}$ ) nanoparticles are also very promising in the field of nanosensor applications [36].

Less numerous are the examples of nanostructures of other materials formed by plasma deposition/processing. Thus, for example, Chen and co-workers [37] have shown the fabrication of metal nanoparticles embedded in dielectric nanofibres and core@shell nanofibres in a sandwich-like microreactor combining $\mathrm{H}_{2}$ plasma with high microwave power and substrate temperatures of $530{ }^{\circ} \mathrm{C}$. Inorganic $\mathrm{n}-\mathrm{p}$ heterojunctions based on $\mathrm{GaN} / \mathrm{InGaN}$ 1D heterostructures have been fabricated by plasma-assisted molecular beam epitaxy and used for the development of light emitting diodes [41]. Formation of complex oxide semiconducting 1D heterostructures have been also recently reported [42]. In this case, a $\mathrm{TiO}_{2}$ shell is deposited by plasma sputtering deposition onto $\mathrm{ZnO}$ nanorods previously deposited by a hydrothermal method. Particularly interesting in this context are also the formation of oxide NFs by the direct interaction of high density plasmas of oxygen on the surface of metals [31]. In previous publications we have also shown that supported $\mathrm{Ag} @ \mathrm{TiO}_{2} \mathrm{NFs}$ are formed at low temperatures when titanium oxide is plasma deposited on a silver metal foil previously treated with oxygen plasma $[46,47]$.

Metal seeds are commonly used by many methods of preparation of supported NFs, particularly those based on chemical routes or the so called vapour-liquid-solid and 
vapour-solid methods (VS) [10-12, 48]. It has been already discussed that metal nanoparticles are used for the plasma fabrication of CNTs and other carbon nanostructures [29]. A common feature of these procedures, usually carried out at relatively high temperatures, is that the metal nanoparticles participate actively in the $\mathrm{NF}$ formation through some catalytically induced phenomena (i.e., by inducing a chemical change in the incoming particles that favour their integration into the fibres) and/or by the dissolution of the nanofibre forming element within the seed particle forming an active alloy that favours the fibre growth $[10-12,30,48,49]$. The case that we would like to deal with in detail in the present work is the use of metal seeds for the plasma formation of composite NFs where no catalytic effect has been detected. This was the case during the preparation of $\mathrm{Ag} @ \mathrm{TiO}_{2}$ nanofibres mentioned above, where the NF growth mechanism was related with the surface mobilisation of the silver and the effect of inhomogeneities of the plasma sheath in inducing a preferential growth of the nanostructures. Recently, the idea that plasma sheaths inhomogeneities can be important in this kind of processes has been claimed to account for the pulsed laser deposition of Ga-doped $\mathrm{ZnO} \mathrm{NFs}$ [50]. In the present work we aim to overview previous results in the area and extend the understanding of morphological features on the formation of oxide NFs by exploring the possibilities of the metal seed methodology for the fabrication of supported 1D heterostructures on processable substrates. For the sake of clarity, we have focussed this study on the morphology of the obtained nanostructures, although differences in crystallinity, density, and other properties have been also found. Examples are shown for metal seeds of $\mathrm{Ag}, \mathrm{Au}$ and $\mathrm{Pt}$ and various oxides $\left(\mathrm{SiO}_{2}, \mathrm{TiO}_{2}\right.$ and $\left.\mathrm{ZnO}\right)$. An extraordinary wealth of different kinds of supported NFs and, in general surface nanostructures, are obtained by modifying the characteristics of the metal seeds (size and percolation degree of particles, equivalent thickness of the metal layer, pretreatment with a plasma of oxygen, etc.) and the deposition temperature, always in ranges much lower than the usual processing temperatures utilize by other vapour or plasma based procedures [23-30]. We also try to give some explanations to account for the observed results where basic processes like stress relaxation, local confinement and deformation of the electric field associated to the plasma sheath, etc. are taken into account. Lacking of theoretical descriptions of these basic phenomena (some recent theoretical works have tried to account for the growth of NFs under plasma but not for their formation as an effect of metal seeds and plasma sheath inhomogeneities [51]), the proposed models are still qualitative and 
phenomenological, although they are able to account for the observed processes and predict new scenarios for the surface nanostructuring of deposited oxides by metal seedmediated plasma enhanced chemical vapour deposition (PECVD).

\section{Experimental plasma processes used for the development of nanostructures}

A full account of the experimental conditions used for the growth and characterization of the oxide nanostructures can be found in the supplementary information. Here we will comment on some basic aspects of the plasma conditions and metal substrate treatment used for the growth of the oxide nanostructures. $\mathrm{TiO}_{2}, \mathrm{SiO}_{2}$ and $\mathrm{ZnO}$ were deposited at various substrate temperatures by PECVD in a plasma reactor with a downstream configuration and using pure $\mathrm{O}_{2}$ or mixtures $\mathrm{Ar}+\mathrm{O}_{2}$ as plasma gas. Titanium tetraisopropoxide (TTIP), hexamethyldisilazane HDMS, and diethyl Zinc (DEZ) were used as a titanium, silicon and zinc oxide precursor respectively. An important parameter for the development of NFs was the substrate temperature during deposition. A threshold temperature of $130^{\circ} \mathrm{C}$ or higher had to be used for NF formation on silver or silver/silicon substrates. Temperature was measured with a thermocouple placed besides the position of the samples.

In most experiments with silver foils or silver layer/particles deposited on silicon, the substrates were previously subjected to a plasma of oxygen in the same chamber used for the deposition of the oxides.

Silver and gold particles/layers were deposited onto the substrates by sputtering from a metal wire placed at $3 \mathrm{~cm}$ from the substrates in a chamber filled with Ar. In some cases substrate temperature during deposition was set a $\mathrm{T}>200{ }^{\circ} \mathrm{C}$ in order to increase the average size of the deposited metal particles. The $\mathrm{Pt} / \mathrm{Si}(100)$ substrates were fabricated by chemical vapor deposition from a $\mathrm{Pt}(\mathrm{acac}) 2$ precursor and posterior annealing at elevated temperatures.

\section{A first step in the synthesis of metal@oxide nanofibres: Control on the micro/nanostructure of oxide thin films.}

Formation of oxide thin films can be considered as a first step for the comprehension of the plasma processes leading to the synthesis of $1 \mathrm{D}$ heterostructures. This section is therefore dedicated to discuss some of the factors controlling the morphology of oxide thin films. 


\subsection{Columnar thin films of $\mathrm{TiO}_{2}$ and $\mathrm{ZnO}$ on flat and non-metal substrates}

Previous studies on plasma deposited $\mathrm{TiO}_{2}$ and $\mathrm{ZnO}$ thin films have shown that they may present different microstructures depending on deposition conditions and particularly on the plasma gas composition [52-57]. Thus, for example, either columnar or homogeneous $\mathrm{TiO}_{2}$ thin films can be obtained by using pure $\mathrm{O}_{2}$ or a mixture $\mathrm{Ar}+\mathrm{O}_{2}$ as plasma gas, respectively [55-57]. The formation of homogeneous thin film microstructures by PECVD has been associated with a growing mechanism where surface diffusion of ad-species is the controlling process [55-57], while the columnar growth has been related with the existence of shadowing effects and a high sticking coefficient of the ad-species coming from the plasma $[55,56,60]$. In connection with this columnar growth of thin films, it has been realized that in PECVD processes the particles arrive with a wide distribution of incoming angles and that the actual angular distribution is a key factor in determining the microstructure developed by the films [58, 59]. Figure 1 shows as an example two cross-section scanning electron microscope (SEM) micrographs obtained for columnar amorphous $\mathrm{TiO}_{2}$ (Fig. 1 a)) and lowcrystallinity columnar $\mathrm{ZnO}$ (Fig. $1 \mathrm{~b}$ )) thin films prepared at $130{ }^{\circ} \mathrm{C}$ with an oxygen plasma and Ti-tetraixopropoxide (TTIP) and diethyl Zinc (DEZ) precursors for the $\mathrm{TiO}_{2}$ and $\mathrm{ZnO}$ respectively as explained in the experimental section. For these two film preparations the highly oxidative character of the plasma ensures that the $\mathrm{Zn}$ or $\mathrm{Ti}$ containing ad-species impinging onto the growing film do not contain carbon in their structure $[55,56]$ and therefore possess a high sticking coefficient.

a)

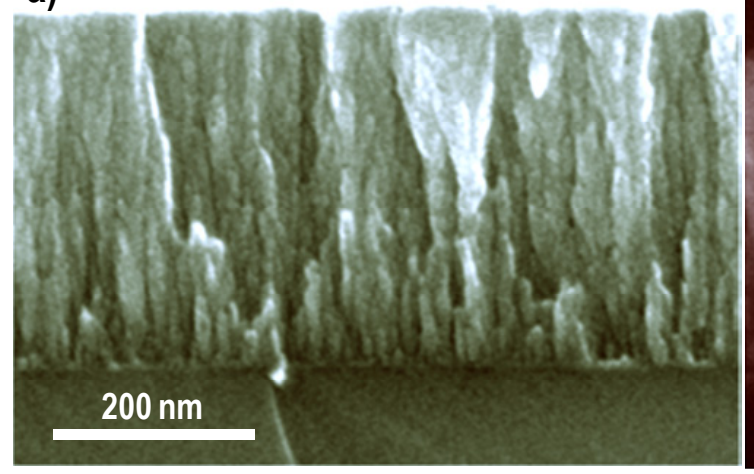

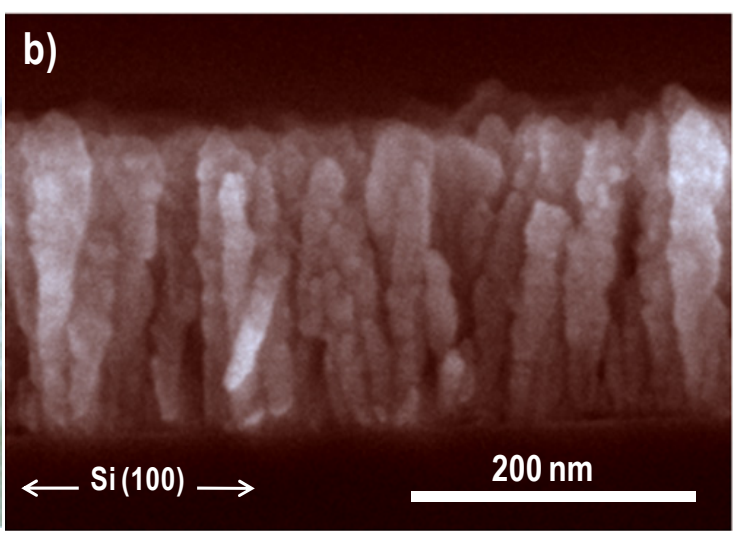

Figure 1. SEM cross sections micrographs of columnar $\mathrm{TiO}_{2}$ (a) and $\mathrm{ZnO}$ (b) thin films deposited by PECVD of a silicon substrate without metal seeds. Both thin films were deposited at $130{ }^{\circ} \mathrm{C}$ under pure oxygen plasma conditions. 
This reduces the relative importance of the diffusion processes of ad-species and favours the development of the observed columnar microstructures. We must note that the obtained films were either amorphous (i.e., $\mathrm{TiO}_{2}$ ) or presented low crystallinity (i.e. $\mathrm{ZnO}$ ), so that crystallization-induced changes in the microstructure can be neglected. This picture can be altered if a crystallization driven process occur during the thin film deposition by PECVD. In case that crystallization occurs (e.g., by increasing the substrate temperature), previous investigations on the PECVD growth of anatase have shown that the thin film microstructure is affected not only by shadowing, diffusion or other similar processes, but mainly by the dynamics of formation of crystallites [60].

\subsection{Metal substrates and crystallinity of metal oxide films}

By the depositions in Fig.1 and, in general, in most works dealing with the formation of oxide thin films, the role of the substrate is usually overlooked, even if evidences exist that its chemical nature and, particularly its metal or insulator character, may have a great importance in determining the microstructure and crystallinity of the films deposited by PECVD. These differences are particularly important during the PECVD growth of crystalline thin films. A clear evidence of the importance of the metal character of the substrate in controlling the crystallinity of the deposited films is provided by the images in Figure $2 \mathrm{a}$ (see also ref. 60). This figure shows a SEM micrograph of the surface of a $\mathrm{TiO}_{2}$ crystalline thin film deposited at $250{ }^{\circ} \mathrm{C}$ on a silicon substrate that had been partially covered by a silver layer. 

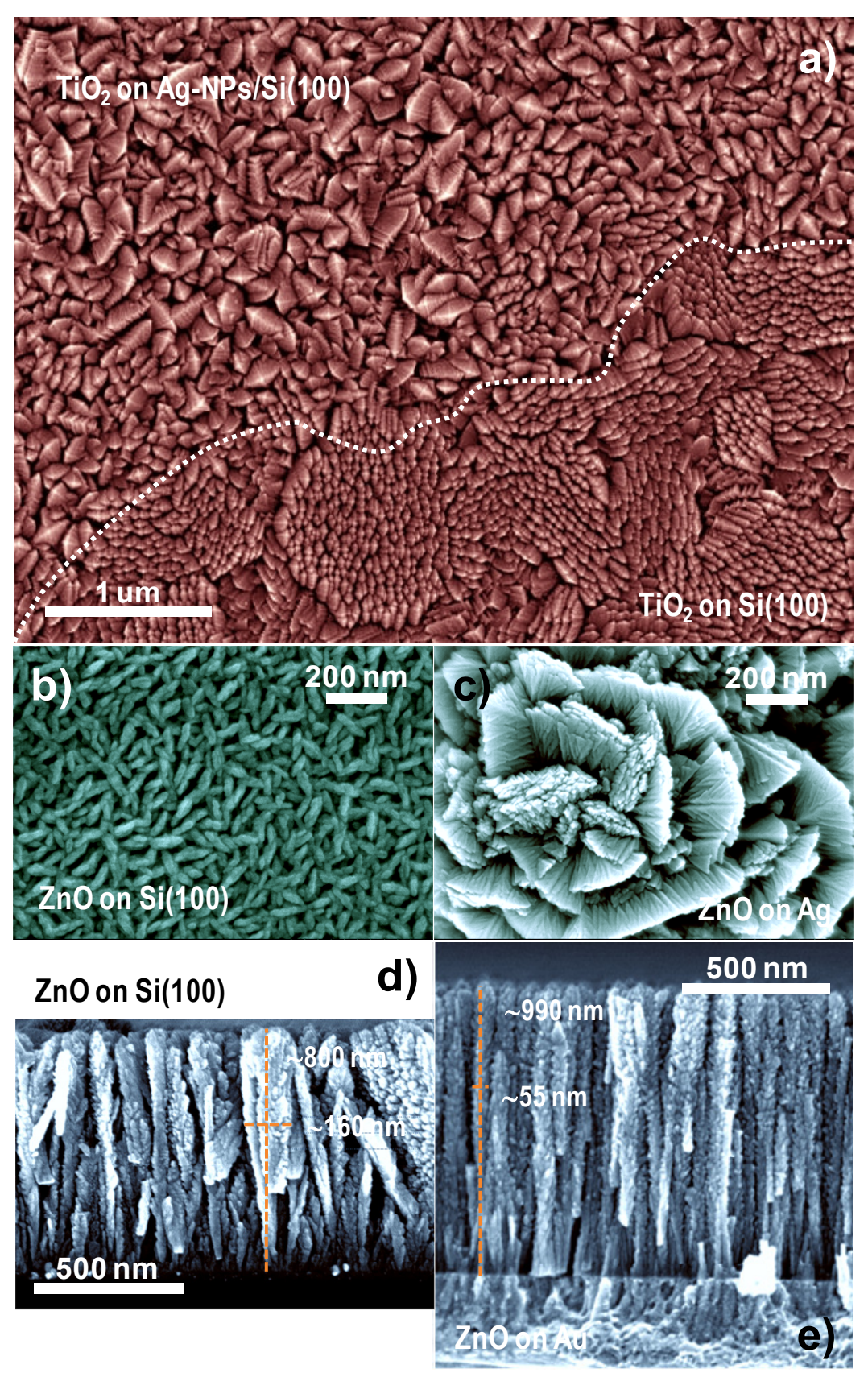

Figure 2. a) SEM micrograph of a crystalline layer of $\mathrm{TiO}_{2}$ deposited on a silicon substrate partially covered by a silver layer (dash line has been included to guide the eyes). b) and c) Normal view SEM micrographs of the $\mathrm{ZnO}$ growth at $130^{\circ} \mathrm{C}$ on $\mathrm{Si}(100)$ and on $\mathrm{Ag}$ foil respectively. d) and e) Cross section SEM image of the $\mathrm{ZnO}$ growth at $250^{\circ} \mathrm{C}$ on $\mathrm{Si}(100)$ and on a gold film respectively. Note that: i) the length of the $\mathrm{ZnO}$ columns grown at $250{ }^{\circ} \mathrm{C}$ on $\mathrm{Au}$ is almost a $125 \%$ higher when compared with the same experiment on $\mathrm{Si}(100)$; and ii) the aspect ratio of the $\mathrm{ZnO}$ columns grown at $250{ }^{\circ} \mathrm{C}$ is $\sim 5$ for the experiments on $\mathrm{Si}(100)$ and $\sim 18$ for the experiments on the Au surface.

The crystalline character of this film and the others films reported in Fig. 2 has been proved by X-ray diffraction (XRD) (data not shown). The micrograph has been taken at the limit of the silver layer to evidence that the film microstructure is completely 
different on the silver covered zone than on the bear silicon substrate. In the former case the $\mathrm{TiO}_{2}$ crystallites are smaller in size and appear randomly oriented on the surface, while in the second they aggregate in certain zones forming well defined crystal columnar habits whose origin can be accounted for by the Kolmogorov model of crystal growth [56]. An enhanced crystallinity of the deposits is also evidenced in Fig. 2b) and c) showing a comparison of the normal view microstructure of $\mathrm{ZnO}$ thin films deposited at $130{ }^{\circ} \mathrm{C}$ on a silicon wafer and on an $\mathrm{Ag}$ foil. In this latter case the crystal size is much higher, an observation that runs parallel with an increase in the size of crystal domains as determined by XRD (data not shown). The clear differences in crystal aspect constitute additional evidence on the effect of a metal on the growth of crystalline films. Significant differences are also found when deposition is carried out on a metal thin layer deposited on a silicon substrate. Some micrographs exemplifying this situation are shown in Figures d) and e), corresponding to crystalline $\mathrm{ZnO}$ thin films deposited at 250 ${ }^{\circ} \mathrm{C}$ on a silicon wafer and on a silicon wafer previously covered with a thin gold layer. In both cases the thin film microstructure is columnar, but in the second the height of the columns and their aspect ratio are much higher than in the former. In summary, these experiments clearly show an enhanced tendency of the crystalline thin films (i.e. anatase and wurtzite phases respectively) of the two oxides to form nanostructures when they are deposited on noble metal layers. Different processes can be tentatively proposed to account for such enhancement in the crystal development: i) a fast crystal development fostered by the crystalline surface of the metal substrate at the very first steps of the crystal growth, i.e. at the nucleation stage [60] and ii) a possible catalytic effect on the growth driven by the metal layer. As we will see in the next section this latter hypothesis must be discarded.

\subsection{Metal islands and the preferential deposition of oxides}

Additional changes in the thin film microstructure are obtained if, instead of a continuous metal layer, the metal deposit is formed by micro or nano-meter size islands that leave uncovered large zones of the substrate. In that case, it is found that the plasma deposition occurs preferentially on the metal particles that act as growing centres of the oxide nanostructures. This behaviour is illustrated in Figure 3 showing a series of cross section micrographs of $\mathrm{TiO}_{2}$ deposited at $130{ }^{\circ} \mathrm{C}$ (i.e., amorphous $\mathrm{TiO}_{2}$ ) and $250{ }^{\circ} \mathrm{C}$ (i.e., crystalline $\mathrm{TiO}_{2}$ ) on silver, gold and platinum particles of different average sizes 
ranging from $10 \mathrm{~nm}$ for $\mathrm{Ag}$ to $\sim 200 \mathrm{~nm}$ for $\mathrm{Pt}$, with intermediate values around $160 \mathrm{~nm}$ for $\mathrm{Au}$.
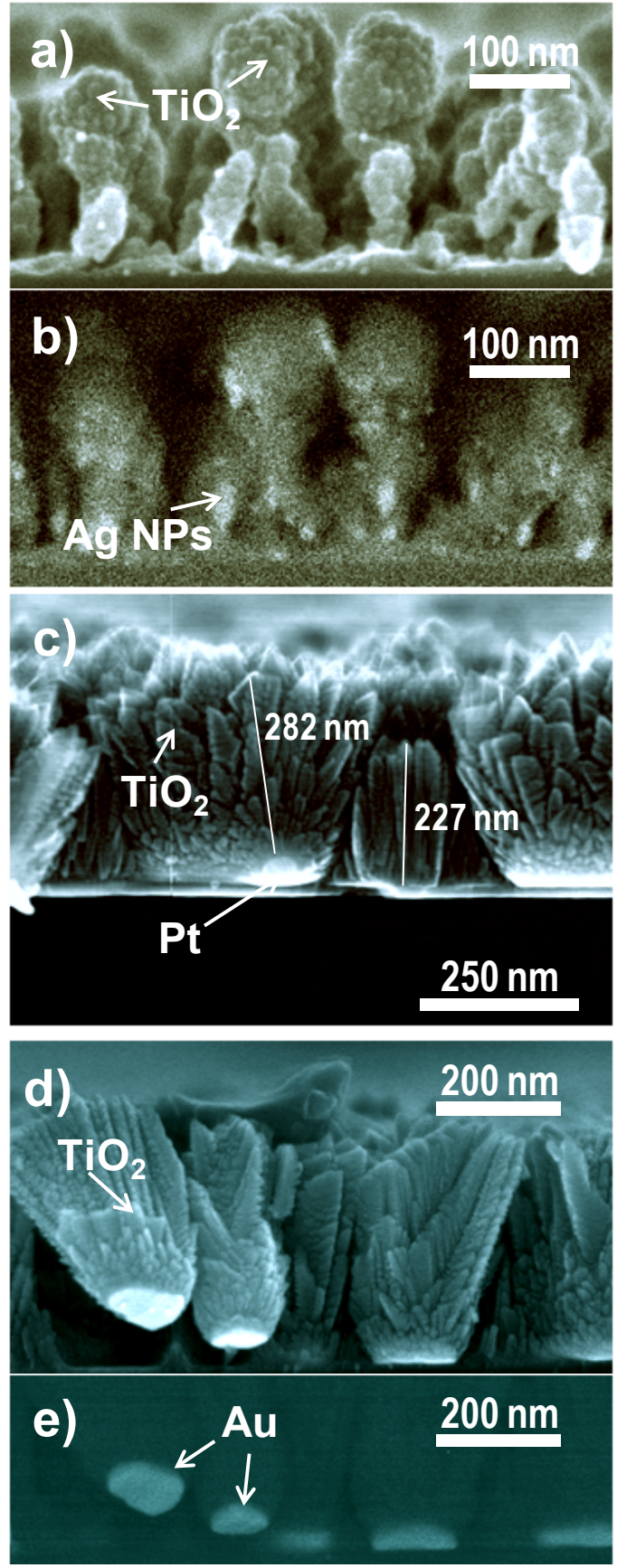

Figure 3. Cross section SEM micrographs of $\mathrm{TiO}_{2}$ deposited at $130{ }^{\circ} \mathrm{C}$ on $\mathrm{Ag} / \mathrm{Si}(100)$ substrates (a) and b) recorded for secondary electrons (SE) and backscattered electrons (BSE) respectively); at $250{ }^{\circ} \mathrm{C}$ on $\mathrm{Pt} / \mathrm{Si}(100)$ substrates (c); and at $250^{\circ} \mathrm{C}$ on $\mathrm{Au} / \mathrm{Si}(100)$ substrates (d) SE image and e) BSE image). In BSE micrographs the bright features correspond to the metal seeds.

The facts that the deposition was carried out at relatively low temperatures as measured by a thermocouple placed at the porthole samples and that no catalytic effect is known for silver, gold or platinum towards the growth of titanium oxide, seem to discard that 
catalytic effects, similar to those claimed for the plasma formation of CNTs [25-30], are involved in the selective deposition of the oxides over the metal particles. This catalytic effect implies the excitation/chemical transformation of the plasma species arriving to the surface by the effect of the metal particles. The processes involved in the formation of the oxide nanofibres are different and must involve other effects likely related with the electrical conductive character of the metal particles. Tentatively, following previous suggestions by several authors $[22,50,51]$, we propose that the electrical field of the plasma sheath developed over the substrate is locally modified by the metal particles in a way that it favors the selective impingement of charged plasma species of partially decomposed precursor molecules onto the metal particles. This would favour a selective drift of the positively charge particles and an increase of the local deposition rate on the nanoparticles. However, this simplistic model does not account for the fate of the neutral species of the plasma arriving to the substrate according to a large range of incoming angles [58]. In this case shadowing effects should be also claimed, particularly by the PECVD of oxides under oxygen rich plasma conditions where adparticles with a high sticking coefficient arrive to the substrate. A brief discussion of this situation for thin film growth has been included in section 2.1. Although these and other fundamental questions are outside the scope of the present work they represent an open topic for the modelling of the plasma sheath, very likely by considering lateral inhomogneities in its electrical field distribution, and the random arrival of neutral particles onto the surface.

\section{Formation of supported core@shell (metal/oxide $\left.\left(\mathrm{Ag} @ \mathrm{TiO}_{2}\right)\right)$ nanofibres}

The use of bulk metal substrates with pronounced surface inhomogeneities favours the development of additional phenomena that contribute to the plasma deposition of oxide nanostructures. $\mathrm{Ag} @ \mathrm{TiO}_{2}$ core@shell NFs have been prepared by $\mathrm{TiO}_{2}$ deposition at $130{ }^{\circ} \mathrm{C}$ over a silver metal foil that had been previously exposed to a plasma of oxygen [46, 47]. Formation of gold-nanoparticle-embedded dielectric nanowires and other related "peapod" nanostructures is an active area of research because of their multiple applications in various fields $[37,61,62]$. In our previous works by plasma deposition it was shown that oxygen plasma treatments provoke the development of silver surface nanostructures and a high accumulation of mechanical stress at its surface because of the higher specific volume of silver oxide as compared with metal silver. On this plasma modified substrate, $\mathrm{TiO}_{2}$ deposition induced the formation of NFs (Fig. 4a) which, 
according to their analysis by transmission electron microscopy (TEM) (Fig. 4b), are formed by a metal core made of a single crystalline silver wire (thickness around 20 $\mathrm{nm}$ ) and an external layer of $\mathrm{TiO}_{2}$. Usually, the length of these fibres is in the range of 2-3 microns and its width depends on the deposition time. $\mathrm{The}^{\mathrm{TiO}_{2}}$ shell can be either amorphous or crystalline and be characterized by a columnar or homogeneous microstructure depending on the deposition temperature and plasma composition.
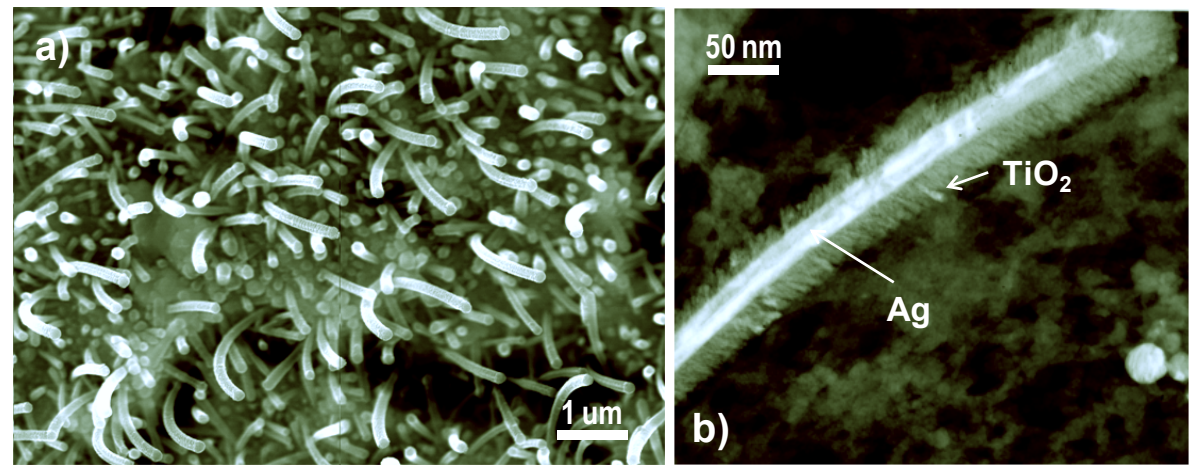

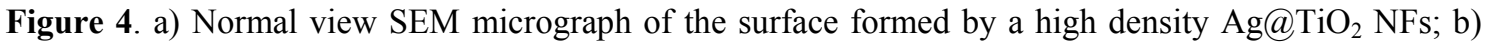
TEM micrograph of an individual $\mathrm{Ag} @ \mathrm{TiO}_{2} \mathrm{NF}$ showing that the core is formed by a silver thread surrounded by a nanocolumnar $\mathrm{TiO}_{2}$ shell.

The formation of these NFs was rationalized by taken into account the following factors, that define what we called a "volcano" type mechanism of formation of supported NFs by plasma deposition [47]:

a) the surface of the bulk silver substrate is heterogeneous due to the oxygen plasma treatment. It is known that silver becomes oxidized when exposed to a plasma of oxygen [64] and that partial decomposition of the oxide into the metal or other oxide phases may occur locally without needing a substantial excitation energy $[65,66]$. In this locally heterogeneous surface, some "hot spots" favour the deposition of the $\mathrm{TiO}_{2}$ which becomes enhanced by plasma sheath inhomogeneities as it happens onto the metal islands as referred in section 3.3.

b) The stress accumulated in the external layers of the oxygen plasma treated silver is released by the formation of a silver wire. The mechanism is similar to that involved in the formation of whiskers in tin plates used for welding conventional electronic components [67]. It is worthy of note that the NFs only develop when this experiment is carried out at $\mathrm{T}_{\text {substrates }} \geq 130{ }^{\circ} \mathrm{C}$, precisely the Huttig temperature of silver at which its atomic mobility is considerably high. 
c) As the silver wire is being formed it becomes covered by $\mathrm{TiO}_{2}$ whose deposition occurs preferentially on the wire walls and significantly at its tip because of the plasma sheath effects already claimed in a). Some models existing in literature on the simulation of a coating growth on nanofibres $[67,68]$ could help to describe this part of the process.

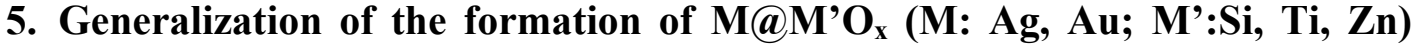 nanofibres}

Plasma formation of $M @ M^{\prime} O_{x}$ nanofibres also occurs with different efficacy for other metal substrate/deposited oxide couples. Fig. 5 shows a series of SEM micrographs corresponding to different types of NFs. Examples are reported in this figure for $\mathrm{Ag} @ \mathrm{TiO}_{2}-\mathrm{SiO}_{2}$, where a mixture of $\mathrm{SiO}_{2}$ and $\mathrm{TiO}_{2}$ is obtained by simultaneously dosing Si and Ti precursors for the deposition, $\mathrm{Ag} @ \mathrm{SiO}_{2}, \mathrm{Au} @ \mathrm{TiO}_{2}$ and $\mathrm{Ag} / \mathrm{ZnO}$. For the first three type of fibres, there are evidences by TEM that the core of the fibre consists of a metal thread. However, in the fourth system, silver seems to be also distributed onto the fibre tips, in a very similar way as metal seeds appear onto oxide fibers grown by the vapour VLS method [10-12]. It must also be noted that for $\mathrm{Ag} @ \mathrm{SiO}_{2}$ and $\mathrm{Au} @ \mathrm{TiO}_{2}$ there is a much smaller surface density of nanofibres than in $\mathrm{Ag} @ \mathrm{TiO}_{2}$ and that the experiment with gold had to be carried out at $\mathrm{T}_{\text {substrates }}>250{ }^{\circ} \mathrm{C}$. It is likely that this lesser efficacy of fiber formation is related with the lower atomic mobility of the metal substrate $(\mathrm{Au})$ and/or because of a lesser efficiency of $\mathrm{SiO}_{2}$ to induce NF growth. In any case, the point to be stressed here is that the mechanism of $\mathrm{NF}$ formation has a general character and that, provided that the right experimental conditions are found, it can be used for the formation of different composite NFs. The case of $\mathrm{Ag} / \mathrm{ZnO} \mathrm{NFs}$ in Fig. 5, even if grown by plasma deposition under conditions similar to those used in the other examples (i.e. a oxygen plasma treated metal foil and $\mathrm{ZnO}$ deposited by PECVD), presents as a peculiarity that metal nanoparticles seem to decorate the outer surface of the nanostructures. Tentatively we propose that the growth mechanism in this case is a mixture of the volcano type mechanism described in the previous section and an additional VLS processes. Further experimental studies are being carried out at present to understand the basic processes involved in this experiment and how they can be altered to get a tailored synthesis of composite NFs. 



$\mathrm{Ag} @ \mathrm{SiO}_{2}$


Figure 5. a) $\mathrm{SEM}$ normal view micrograph of $\mathrm{Ag} @ \mathrm{TiO}_{2} / \mathrm{SiO}_{2} \mathrm{NFs}$ fabricated at $130{ }^{\circ} \mathrm{C}$ by the simultaneous deposition on the $\mathrm{Ag}$ membrane of $\mathrm{TiO}_{2}$ and $\mathrm{SiO}_{2}$; b) $\mathrm{Ag} @ \mathrm{SiO}_{2} \mathrm{NF}$ deposited at $130{ }^{\circ} \mathrm{C}$. In both a) and b) experiments the substrates were subjected to the same oxygen plasma pre-treatment procedure used for the growth of $\mathrm{Ag} @ \mathrm{TiO}_{2}$ NFs in Fig. 3; c) and d) SEM micrographs of $\mathrm{Au} @ \mathrm{TiO}_{2} \mathrm{NFs}$ fabricated on a gold film of thickness $\sim 500 \mathrm{~nm}$ at $250{ }^{\circ} \mathrm{C}$. The micrograph in panel d) shows a broken NF where the metal core is easily appreciable. e) and f) SE and BSE SEM images respectively of Ag/ZnO NWs grown on an $\mathrm{Ag}$ foil by deposition at $135^{\circ} \mathrm{C}$. Note that the silver particles seem to be on along the $\mathrm{ZnO} \mathrm{NW}$ and that a homogeneous thread is not appreciable inside the nanostructure.

\section{Towards processable substrates}

The previous substrates consisting of a bulk or a very thick metal layer cannot be processed easily and its use for many practical applications is not straightforward. With the intention of developing a methodology suitable for application at an industrial scale for nanotechnological applications, we have carried out a set of experiments to get nanostructured metal-oxide supported nanofibres on conventional substrates (e.g., silicon wafers, floated glass or flat quartz plates, etc.) which are processed according to classical physical vapour deposition and/or plasma technologies. A way to achieve this 
goal is to play with the amount, percolation degree and type of the deposited metal particles and/or thickness of the thin metal film deposited onto conventional substrates. The application of a previous plasma oxidation treatment to these modified substrates is another variable that can be also used. Thus, different kinds of metal nanoparticles/thin films were deposited on silicon or quartz and then subjected to oxygen plasma treatments for various periods of time prior to the PECVD deposition of $\mathrm{ZnO}$ or $\mathrm{TiO}_{2}$. Oxide depositions were always carried out at the critical temperature of $130{ }^{\circ} \mathrm{C}$ or above. Herein, to advance in the comprehension of the basic processes involved in the synthesis of the obtained nanostructures, we will concentrate on two examples. Fig. 6 shows the cross section SEM micrographs of $\mathrm{TiO}_{2}$ and $\mathrm{ZnO}$ supported nanostructures deposited on a silicon substrate with silver on its surface.



Figure 6. a) and b) SE cross section and BSE cross section images respectively of $\mathrm{Ag} @ \mathrm{TiO}_{2}$ nanofibres deposited on a $\mathrm{Si}(100)$ wafer; c) and d) Idem of $\mathrm{Ag} / \mathrm{ZnO}$ nanowires deposited on $\mathrm{Si}(100)$.

These two samples consists of perpendicular arrays of NFs of approximately $90 \mathrm{~nm}$ and $50 \mathrm{~nm}$ width, $900 \mathrm{~nm}$ and $600 \mathrm{~nm}$ long and with a surface density of approximately $8 \mathrm{x}$ $10^{8} \mathrm{NFs} \mathrm{cm}^{-2}$ and for the $\mathrm{TiO}_{2}$ and $70 \times 10^{8} \mathrm{NFs} \mathrm{cm}^{-2} \mathrm{ZnO}$, respectively. It is clear in these micrographs that the oxide NFs grow out from the silver metal particles that act as a seed for the fibre development. However, in comparison with the experiments in Figs. 4 and 5, a significant difference of the microstructure of these supported NFs, besides their irregular character, is that they do not integrate a well defined metal thread in its core as it is shown in Figure 7. This difference suggests that formation of such metal 
wire requires a considerable supply of metal and that shortage in this supply occurs when using dispersed metal islands to act as a seed of NF formation.

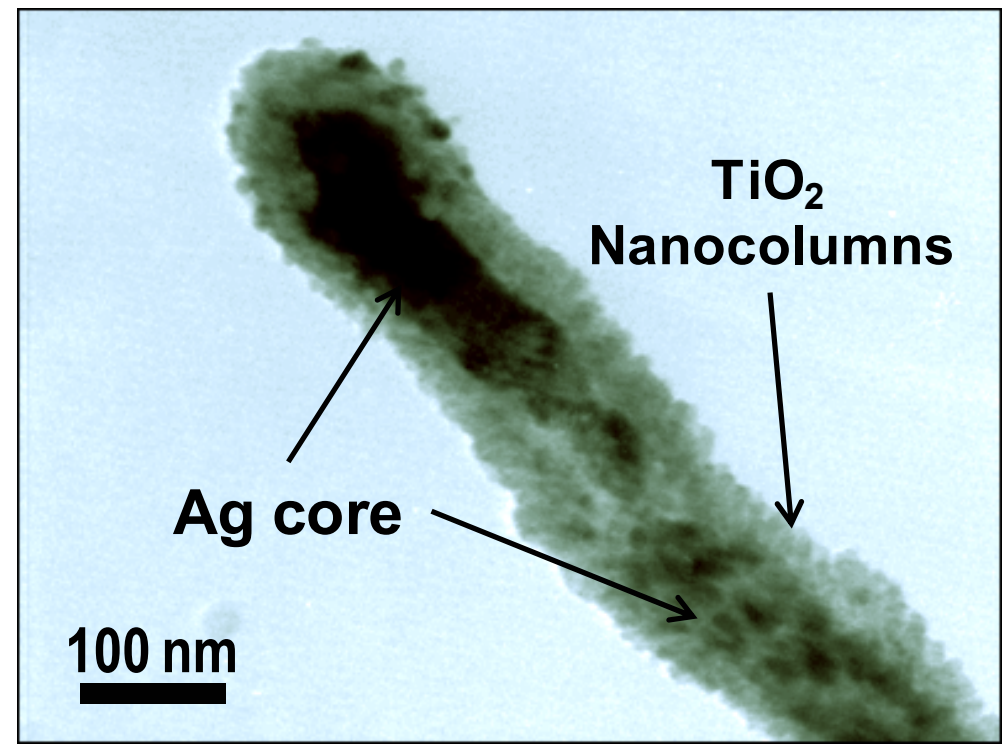

Figure 7. a) TEM image of an individual $\mathrm{Ag} @ \mathrm{TiO}_{2} \mathrm{NF}$ fabricated on $\mathrm{Ag} / \mathrm{Si}(100)$. The $\mathrm{TiO}_{2}$ shell is amorphous and nanocolumnar.

Nevertheless, the most important result from this experiment is that oxide NFs are formed at relatively low temperatures on silver particles. Another important result is that silver nanoparticles become embedded within the NFs, a feature that opens the use of these nanostructures for many different applications in photonics and other fields [62, $63]$.

\section{Prospects and potential applications}

The previous experiments have shown that noble metals can be efficiently used as seeds for the growth of hybrid oxide NFs and other deposited nanostructures. However, while the comprehension of the basic phenomena involved in the nanostructuring of PECVD oxide thin films in the absence of metals is relatively well understood [44-49], the effects induced by the presence of the metal are not yet clear and only phenomenological models exist to account for the development by plasma deposition of the NFs and related nanostructures $[22,30,47,51]$. In relation with the results reported here, we believe that a thorough description of the plasma sheath inhomogeneities induced by the presence of the metal seeds is a critical step in the comprehension of the plasma formation of core@shell metal/oxide NFs. We are convinced that the development of these models would help finding the experimental conditions required for a straightforward control of the formation of the final nanostructures. Despite this 
lack of theoretical interpretation, we have shown that on a trial and error basis well reproducible results can be obtained and different types of NFs and other supported oxide nanostructures formed by PECVD at relatively low temperatures. In addition, compared with other oxide nanostructures formed by very intense plasma treatments $[24,31]$ and/or by catalytically driven processes [10-12], we have shown that our experimental protocols are based on relatively low temperature and mild plasma conditions. These are basic requirements for their use with sensitive substrate and an efficient control of the final process. Because of these reasons advances are foreseen in implementing modifications leading to the formation of other hybrid (organic-oxide) structures or the performance of well controlled lithographic depositions. The control of the electronic structure (i.e., doping) of the deposited nanostructures is another step required for the implementation of the deposited nanostructures for real applications.

In relation with that, and precisely at the present stage of development of the plasma methodology based on metal seeds, we think that it is quite pertinent to briefly discuss its potential practical applications. Thus, former studies have shown that the $\mathrm{Ag} @ \mathrm{TiO}_{2}$ nanofibre surfaces described in section 3 are superhydrophobic (water contact angles (WCA) higher than $150^{\circ}$ ) but can be converted in superhydophilic (water contact angles virtually $0^{\circ}$ ) by UV light irradiation [69]. Changes in $\mathrm{WCAs}$ when $\mathrm{TiO}_{2}$ and other oxides are subjected to UV irradiation are generally attributed to reversible modifications in the surface hydroxylation state and/or the removal by photo-oxidation of surface carbonaceous species [70]. The implications of this behaviour for microfiltration and, in general, microfluidic are obvious [71, 72]. However, potential applications are not restricted to the interaction with fluids, the implementation of $\mathrm{TiO}_{2}$ and $\mathrm{ZnO}$ nanostructures as sensors, luminescent devices, piezoelectric brushes, electrodes for electrochemical and photo-electrochemical cells, dye sensitized or hybrid photovoltaic solar cells, etc. are direct niches of application and their use could provide significant improvements of the present figure of merit of such devices [10-12, 19-21, 73]. We hope that future improvement in the PECVD processes and their understanding can contribute to a tailored synthesis of oxide directly usable in these fields. In our opinion, a very promising way for a versatile fabrication of core@shell nanostructures is the combination of conformal thin films or layers deposited by plasma methods onto previously grown 1D nanostructures [see also refs. 42-45]. Furthermore, the utilisation of low substrate temperature and remote plasma reactors for the fabrication of the shell materials make such methodology compatible with the deposition onto sensitive 
substrate, e.g. polymer nanofibres. Finally, owing to the ease change in composition of the oxide phase achievable by using plasma processes, the preparation of customized 1D nanostructures with $p-n$ junctions or other interfaces is another option which would deserve further attention for their use in advanced applications.

\section{Acknowledgments}

This work was funded by the EU (project NMP3-CT-2006-032583), the Spanish MICINN (projects MAT 2007-65764, MAT2010-18447, MAT2010-21228 and Consolider CSD2008-00023) and JUNTA de Andalucía (projects P09-TEP-5283, CTS5189).

\section{References}

[1] Ensinger W 1998 Surf. Coat. Technol. 99 1-13

[2] Tsai R Y, Shiau S-C, Lee C H, Cho F, Hua M-Y 1997 Opt. Engn. 363433

[3] Leinen D, Espinos J P, Fernandez A, Gonzalez-Elipe A R 1994 J. Vac. Sci. Technol. A 12, 2728-2732

[4] Gonzalez-Garcia L, Lozano G, Barranco H, Gonzalez-Elipe A R 2010 J. Mater. Chem. 20 6408-6412

[5] Chattopadhyay S, Huang Y F, Jen Y J, Ganguly A, Chen K H, Chen L C 2010 Mater. Sci. Eng. R 69 1-35

[6] Choukourov A, Solar P, Polonskyi O, Hanus J, Drabik M, Kylian O, Pavlova E, Slavinska D, Biederman H 2010 Plasma Proc. Polym. 7 25-32

[7] Mieszawska A J, Jalilian R, Sumanasekera G U, Zamborini F P 2007 Small 3722

[8] Achard M-F, Maquet J, Steunou N, Livage J, Serier H, Backov R 2005 Adv. Mater. $172970-2974$

[9] Kapadia R, Ko H, Chueh Y-L, Ho J C, Takahashi T, Zhang Z, Javey A 2009 Appl. Phys. Lett. 94263110

[10] Yan R, Gargas D, Yang P 2009 Nature Photonics 3 569-76

[11] Yang P, Yan R, Fardy M 2010 Nanolett. 10 1529-36

[12] Barth S, Hernandez-Ramirez F, Holmes J D, Romano-Rodriguez A 2010 Prog. Mater. Sci. 56 263-627

[13] Macak J M, Tsuchiya H, Ghicov A, Schmuki P 2005 Electrochem. Comm. 7 113337 
[14] Wacaser B A, Dick J A, Johansson J, Borgstrom M K, Deppert K, Samuelson L 2008 Adv. Mater. 20 1-13

[15] Peng P, Milliron D J, Hughes S M, Johnson J C, Alivisatos A P 2005 Nano Lett. 5 1809

[16] Carny O, Shalev D E, Gazit E 2006 Nano Lett. 61594

[17] Borras A, Groening O, Aguirre M, Lopez-Cartes C, Groening P 2008 Chem. Mater. $207371-7373$

[18] Borras A, Groening O, Koeble J, Groening P 2009 Adv. Mater. 21 4816-4819

[19] Mieszawska A J, Jalilian R, Sumanasekera G U, Zamborini F P 2007 Small $3722-$ 56

[20] Rao C N R, Govindaraj A 2009 Adv. Mater. 21 1-26

[21] Ma R, Sasaki T, Bando Y c) Chopra N 2010 Mater. Technol. 25 212-30

[22] Mariotti D, Ostrikov K 2009 J. Phys. D: Appl. Phys 42092002

[23] Mozetic M, Cvelbar U, Sunkara M K, Vaddiraju S 2005 Adv. Mater. 172138

[24] Liu X, Wu X H, Cao H, Chang R P H 2004 J. Appl. Phys. 953141

[25] Mariotti D, Mohan R, Sankaran R M 2010 J. Phys. D: Appl. Phys. 43323001

[26] Tsakadze Z L, Levchenko I, Ostrikov K, Xu S 2005 Carbon 452022

[27] Tam E, Ostrikov K 2008 Appl. Phys. Lett. 93261504

[28] Kumar S, Levchenko I, Keidar M, Ostrikov K 2010 Appl.Phys.Letters 97151503

[29] Meyyappan M 2009 J. Phys. D: Appl. Phys. 42, 213001

[30] Zheng J, Yang R, Xie L, Qu J, Liu Y, Li X 2010 Adv. Mater. 221451

[31] Ostrikov K, Levchenko I, Cvelbar U, Sunkara M, Mozetic M 2010 Nanoscale 2 2012

[32] Qi J L, Wang X, Tian H W, Liu C, Lu Y L, Zheng W T 2009 Appl. Surf. Sci. 256 $1486-91$

[33] Uh H S, Park S, Kim B 2010 Diamond Related Mater. 19 586-89

[34] Penza M, Rossi R, Alvisi M, Signore M A, Cassano G, Dimaio D, Pentassuglia R, Piscopiello E, Serra E, Falconieri M 2009 Thin Solid Films 517 6211-16

[35] Penza M, Rossi R, Alvisi M, Cassano G, Serra E 2009 Sensor Actuators B

140 176-184

[36] Penza M, Rossi R, Alvisi M, Serra E 2010 Nanotechnol. 21105501

[37] Hu M S, Chen H L, Shen C H, Hong L S, Huang B R, Chen K H, Chen L C 2006 Nature Mater. 5 102-6

[38] Turba T, Norton G, Niraula I, McIlroy D N 2009 J. Nanopar. Res. 11 2137-43 
[39] LaLonde A D, Norton M G, Zhang D, Gangadean D, Alkhateeb A, Padmanabhan R, McIlroy D N 2006 J. Nanopar. Res.8 99-104

[40] Shi D L, Lian J, He P, Wang L M, Xiao F, Yang L, Schulz M J, Mast D B 2003 Appl. Phys. Lett. 83 5301-03

[41] Guo W, Zhang M, Banerjee A, Bhattacharya P 2010 Nano Lett. $103355-59$

[42] Wang M L, Huang C G, Cao Y G, Yu Q J, Guo W, Liu Q L, Liang J K, Hong M C 2009 Nanotechnol. 20285311

[43] Ra H W, Choi D H, Kim S H, Im Y H 2009 J. Phys. Chem. C 113 3512-16

[44] He J H, Ho C H, Chen C Y 2009 Nanotechnol. 20065503

[45] Tak Y, Yong K 2005 Surf. Rev. Lett. 12 215-19

[46] Borras A, Barranco A, Yubero F, Gonzalez-Elipe A R 2006 Nanotechnol. 17 $3518-22$

[47] Borras A, Barranco A, Espinos J P, Cotrino J, Holgado J P, Gonzalez-Elipe A R

[48] Xia Y, Sun Y, Wu Y, Mayers B, Gates B, Yin Y, Kim F, Yan H 2003 Adv. Mater. 15353

[49] Singh M K, Titus E, Gracio J 2010 J. Nanosci. Nanotechnol. 102764 2007 Plasma Procc. Polym. 4 515-27

[50] Yan M, Zhang H T, Widjaja E J, Chang R P H 2004 J. Appl. Phys. 945240

[51] Moore K, Clemons C B, Kreider K L, Young G W 2007 J. Appl. Phys. 101064305

[52] Martin A, Espinos J P, Justo A, Holgado J P, Yubero F, Gonzalez-Elipe A R 2002 Surf. Coat. Technol. 151 289-93

[53] Barranco A, Cotrino J, Yubero F, Espinos J P, Benitez J, Clerc C, Gonzalez-Elipe A R 2001 Thin Sol. Films 401 150-158

[54] Barranco A, Cotrino J, Yubero F, Girardeau T, Camelio S, Gonzalez-Elipe A R 2004 Surf. Coat. Technol. 180 244-249

[55] Borras A, Cotrino J, Gonzalez-Elipe A R 2007 J. Electrochem. Soc. 154 152-154

[56] Borras A, Sanchez-Valencia J R, Garrido-Molinero J, Barranco A, Gonzalez-Elipe A R 2009 Micro Meso Mater. 118 314-19

[57] Borras A, Yanguas-Gil A, Barranco A, Cotrino J, Gonzalez-Elipe A R 2007 Phys. Rev. B 76 235303-1/8

[58] Yanguas-Gil A, Cotrino J, Barranco A, Gonzalez-Elipe A R 2006 Phys. Rev. Lett. 96236101

[59] Alvarez R, Romero-Gomez P, Gil-Rostra J, Cotrino J, Yubero F, Palmero A, Gonzalez-Elipe A R 2010 J. Appl. Phys. 108064316 
[60] Borras A, Sanchez-Valencia J R, Widmer R, Rico V J, Justo A, Gonzalez-Elipe A R 2009 Cryst. Growth Design 9 2868-76

[61] Smith B W, Montioux M, Luzzi D E 1998 Nature 396323

[62] Wu JS, Dhara S, Wu CT, Chen KH, Chen YF, Chen LC 2002 Adv. Mater. 14 $1847-50$

[63] Yoon P Y G, Mazzoni M S C, Louie S G 2003 Appl. Phys. Lett. 835217

[64] Bhan M K, Nag P K, Miller G P, Gregory J C 1994 J. Vac. Sci.Technol. A 12699

[65] Pierson J F, Rousselot C 2005 Surf. Coat. Technol. 200276

[66] Gao X Y, Wang S Y, Li J, Zheng Y X, Zhang R J, Zhou P, Yang Y M, Chen LY 2004 Thin Solid Films 455 438-42

[67] Seng G T T, Hu C F, Choi W J, Tu K N, Bong Y Y, Nguyen L 2002 J. Appl. Phys. $9264-69$

[68] Buldum A, Clemons C B, Dill L H, Kreider K L, Young G W, Zheng X, Evans E A, Zhang G, Hariharan S I 2005 J. Appl. Phys. 98044304

[69] Borras A, Barranco A, Gonzalez-Elipe A R 2008 Langmuir 24 8021-26

[70] Rico V, Romero P, Hueso J L, Espinós J P, González-Elipe A R 2009 Catal. Today 143, 347-354

[71] Blossey R 2003 Nature Mater. 2 301-306

[72] Barthlott W, Schimmel T, Wiersch S, Koch K, Brede M, Barczewski M, Walheim S, Weis A, Kaltenmaier A, Leder A, Bohn H F 2010 Adv. Mater. 22 2325-28 [73] Kapadia R, Ko H, Chueh Y L, Ho J C, Takahashi T, Zhang Z, Javey A 2009 Appl. Phys. Lett. 94263110 


\title{
Supplementary Information
}

\section{Supported plasma made 1D heterostructures: perspectives and applications.}

\author{
Ana Borras, * Manuel Macias-Montero, Pablo Romero-Gomez and Agustin R. \\ Gonzalez-Elipe \\ Materials Science Institute of Seville (CSIC-Universidad Sevilla), C/ Américo Vespucio \\ 49 41092, Sevilla (Spain)
}

\section{Experimental}

$\mathrm{TiO}_{2}, \mathrm{SiO}_{2}$ and $\mathrm{ZnO}$ were deposited at various substrate temperatures by PECVD in a plasma reactor with a downstream configuration. The experimental setup, described in a previous work [39-41], consists of a remote plasma source (SLAN from Plasma consult Gmbh, Germany) attached to a deposition chamber where the deposition is carried out. The source was operated with a power of $400 \mathrm{~W}$ with either pure $\mathrm{O}_{2}$ or mixtures $\mathrm{Ar}+\mathrm{O}_{2}$ $(80 \%$ or $90 \%$ Ar) as plasma gas. Titanium tetraisopropoxide (TTIP), hexamethyldisilazane HDMS, and diethyl Zinc (DEZ) were used as a titanium, silicon and zinc oxide precursor respectively. Due to low vapor pressure of the titanium precursor at room temperature, it was placed in a heated stainless steel recipient while oxygen ( $10 \%$ of the total flow of gases) was bubbled through it. Both the bubbling line and the shower-type dispenser used to dose the precursor into the chamber were heated at $100{ }^{\circ} \mathrm{C}$ to prevent any condensation in the tube walls. The zinc and silicon precursors, having enough vapor pressure at room temperature, were directly dosed into the deposition chamber by means of a mass flow controller and a heated gas line (at 100 $\left.{ }^{\circ} \mathrm{C}\right)$. An important parameter for the development of NFs was the substrate temperature during deposition. Generally a threshold temperature of $130^{\circ} \mathrm{C}$ or higher had to be used for NF formation on silver or silver/silicon substrates. The actual temperature used in each particular case is specified in the text.

Total pressure during deposition was $\sim 4 \times 10^{-3}$ Torr either with pure $\mathrm{O}_{2}$ or $\mathrm{Ar}+\mathrm{O}_{2}$ mixtures as plasma gas. Films were deposited simultaneously on several substrates (approximately $1 \times 1 \mathrm{~cm}^{2}$ size) intended for different characterization tests and to control the development of NFs. 
In some of the experiments with silver foils or silver layer/particles deposited on silicon, the substrates were subjected to a plasma of oxygen prior to the deposition of the oxides. For this treatment we used the same chamber used for the PECVD of the oxides, before deposition was carried out. For this pre-treatment the source was fed with oxygen at a pressure of $\sim 4 \times 10^{-3}$ Torr.

Pieces of silicon and fused silica substrates, silver foils and silicon covered with metal (Ag, Pt and $\mathrm{Au}$ ) films or nanoparticles have been used depending on the intended experiment. Silver and gold were deposited onto the silicon substrates by sputtering from a metal wire placed at $3 \mathrm{~cm}$ from the substrates in a chamber filled with $\operatorname{Ar}(1.12-$ 1.5 Torr). A voltage of $400 \mathrm{~V}$ was applied for the metal sputtering. In some cases substrate temperature during deposition was set a $\mathrm{T}>200{ }^{\circ} \mathrm{C}$ in order to increase the average size of the deposited metal particles. The $\mathrm{Pt} / \mathrm{Si}(100)$ substrates were fabricated by chemical vapor deposition from a $\mathrm{Pt}(\mathrm{acac}) 2$ precursor at temperatures between 370 $390{ }^{\circ} \mathrm{C}$, followed by annealing at $600{ }^{\circ} \mathrm{C}$ in an Ar atmosphere.

Normal and cross-section SEM characterizations of the films/structures grown on silicon were carried out in a Hitachi S4800 and Hitachi S5200 instruments. TEM analysis of nanofibres was carried out in a Phillips CM200 set up. 